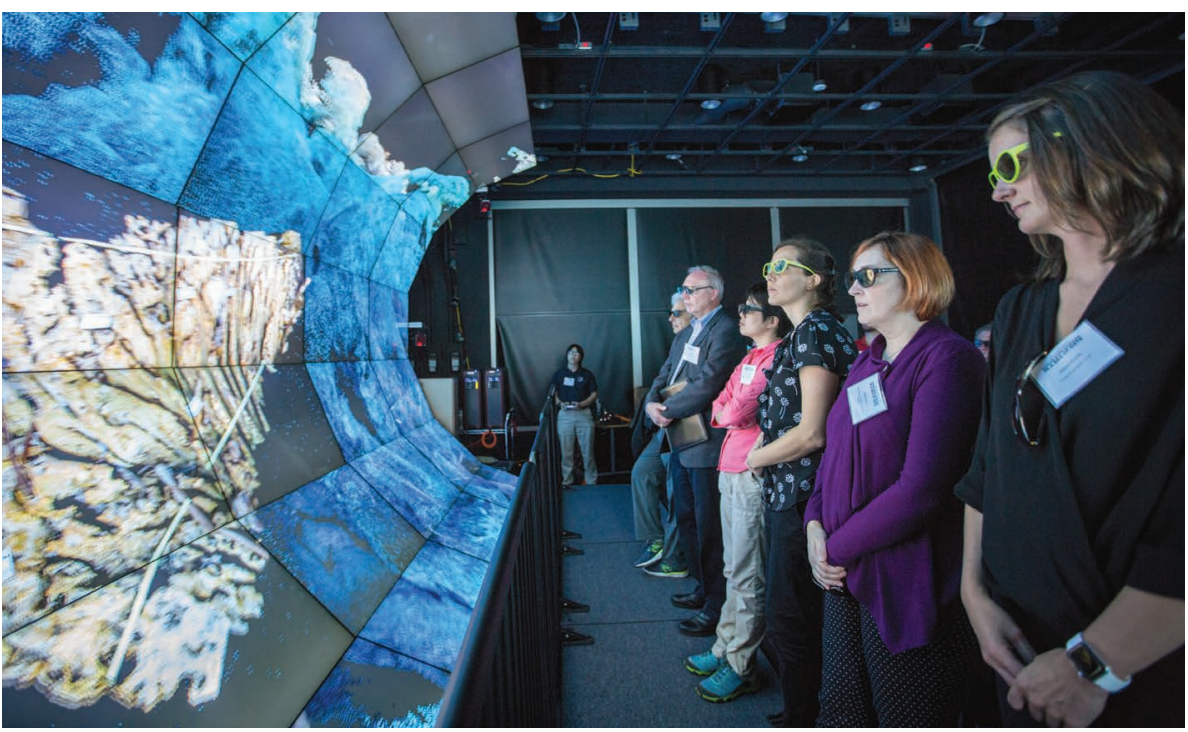

The 3D visualization system known as WAVE, is one of the technologies in use to explore ocean worlds.

\title{
GRAVITATIONAL PULL
}

\section{Interdisciplinary encounters across the geosciences are yielding new insights into the workings of Earth and beyond.}

\section{BY SARAH DEWEERDT}

$\mathrm{J}$ ohn Delaney is an oceanographer and marine geologist, but it's not hard to get him riffing about the outer reaches of the solar system. He is eloquent on Jupiter's moon Europa, with its ocean up to 150 kilometres deep underneath 10 to 15 kilometres of ice, and Saturn's moon Enceladus, with its geysers of water and hydrogen at the south pole, for example.

Delaney, a professor at the University of Washington in Seattle, led an effort to install a permanent network of fibre-optic cables, sensors, and instruments off the Oregon coast that since 2016 has enabled scientists to gather continuous data on the dynamics of the sea floor. Curious members of the public can watch in real time to see, for example, animal behaviour, tidal cycles and an actively venting hydrothermal chimney.

These and other technologies to study the deep sea "could sooner or later be exported and function very effectively in an ocean on another planet," Delaney says. "That kind of collaborative environment for developing off-planet exploration in oceans beyond Earth is one of the things that excites me the most."

Delaney's enthusiasm reflects growing links between oceanography and planetary science, just one manifestation of a strengthening gravitational pull between disciplines that is being felt throughout the geosciences, and indeed throughout Earth and environmental sciences, as shown in the infographic opposite. For researchers, the most exciting questions are the ones that transcend old academic boundaries.

The conviction that if life exists outside Earth, an ocean is a good place to look for it, is a key driver for collaboration between deep sea and outer space research. The possibility of identifying an independent origin of life "is at the heart of what motivates our interest in these ocean worlds," says Kevin Hand, an astrobiologist at the Jet Propulsion Laboratory in California. "Is there another game in town?"

Deep ocean and space scientists also face similar technical challenges in building and running the precisely engineered devices needed to explore terrain under extreme conditions.

\section{OUT OF THIS WORLD}

For planetary scientists, ocean exploration offers a chance to test technologies and ideas more quickly and cheaply than is possible on a space mission. For oceanographers, the example of space science pushes them to make their instruments smaller, lighter, and more autonomous, reducing their reliance on the traditional big research ships.

"We're basically taking robots and putting them in harm's way, and then doing cuttingedge research in places nobody's ever been before," says Christopher German, an oceanographer at Woods Hole Oceanographic Institution in Massachusetts.

Hand and German are frequent collaborators: in 2016, the two took an expedition to look for life under the Arctic ice. They saw it as a way of learning more about our own planet as well as a trial run for exploring other ocean worlds like Europa. The expedition yielded proof of concept that a robotic vehicle can operate under solid ice cover, as well as clues about how seawater percolating through cracks in the seafloor could help sustain life in the absence of sunlight.

Another arena for interdisciplinary research in the geosciences is the effort to understand how the movements of tectonic plates have affected the Earth's atmosphere and climate. Studying what shapes the atmosphere is inherently interdisciplinary because the atmosphere is "an integrator of all of the processes that are happening on Earth, both biotic and tectonic," says Noah Planavsky, a geologist at Yale University in Connecticut.

Volcanic activity triggered by subduction when the edge of one tectonic plate slides under another - can release large amounts of carbon dioxide into the atmosphere. Recently, scientists have found evidence that carbon dioxide can also come from volcanic eruptions in the middle of continental plates as they pull apart in rifting zones.

Variations in the intensity of volcanic activity - what Planavsky calls "the pulse of the Earth" - may have driven past climate transitions. And the slow cycling of carbon between the crust, mantle, and atmosphere may have buffered fluctuations in atmospheric carbon dioxide over geologic timescales, helping to explain why the Earth's temperature has remained within a zone that is compatible with life.

The geosciences are also collaborating with other disciplines. For example, geologists are working more frequently with economists and other social scientists to make mining more environmentally friendly and fair. This is prompted by the realization that a lot of cleanenergy technologies such as wind turbines and solar panels rely heavily on metals that are nonrenewable and costly to extract. New sources of metals are also needed to provide infrastructure and goods to an increasingly urban population.

Economists can provide advice on when it is financially feasible to mine a particular deposit, and how to structure royalty and tax schemes to encourage companies to act in the most sustainable way, says Kathleen Segerson, an environmental economist at the University of Connecticut. "How to design the rules to ensure that the mining activities are simultaneously profitable for the firms that want to undertake them, but protective of the environment?" she says. "While clearly technology plays an important role, these are inherently social questions."

Many researchers working in the geosciences today foresee even more interdisciplinary work. The next generation of scientists won't even recognize the boundary between oceanography and planetary sciences, German says. Researchers would range along a continuous spectrum of expertise, from the physical to the chemical and life sciences, he says. "And, in that context then, Earth is just one of the worlds with oceans that it's really interesting to learn more about." - 


\section{GREEN CONNECTIONS}

Earth and environmental sciences are highly interdisciplinary, as the multiple node colours on this graphic show. Each of the 4,070 nodes in this network represents an individual author who has collaborated with at least 40 other authors on Earth and environmental science articlès published in journals tracked by the Nature Index between 2012 and 2017. The size of the nodes denotes the number of co-authors for each author. Denser clusters indicate higher frequency of collaboration between those authors. Authors are coloured according to their primary discipline.

size

$$
=
$$

$$
\text { (1) }
$$$$
\therefore \because \because
$$
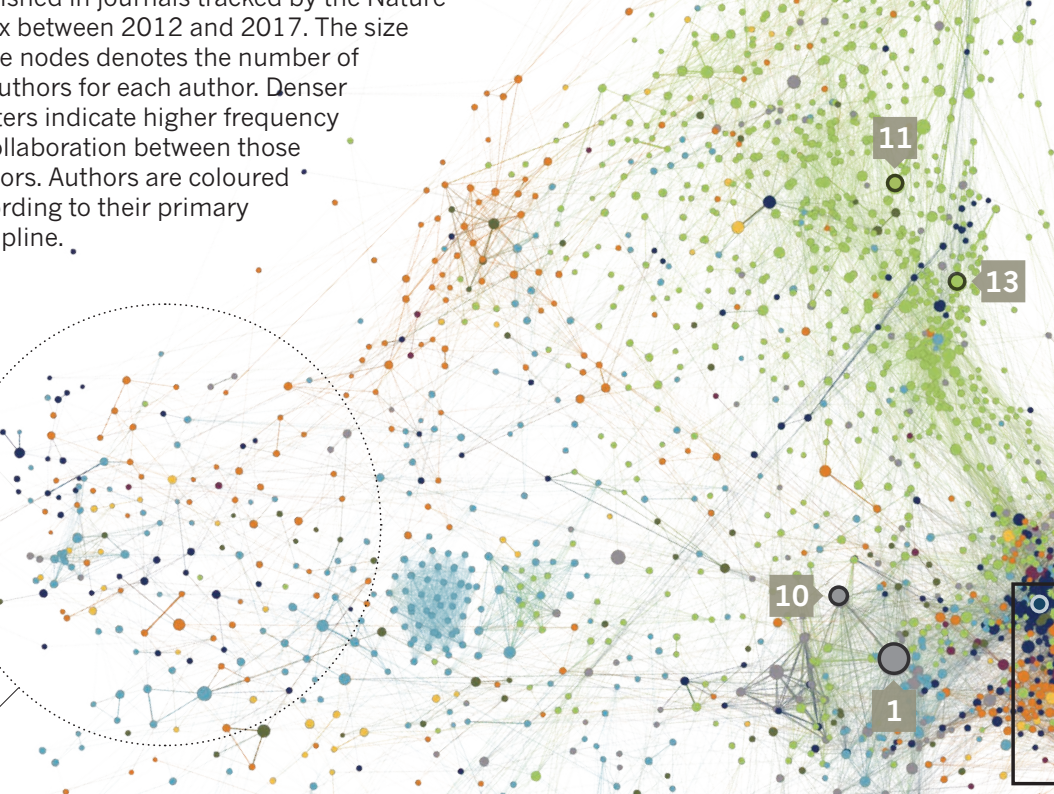

The even spread and diverse mix of disciplines in this area, and the near absence. of researchers in Earth and environmental sciences, shows authors collaborating across engineering, biological, medical and health sciences on environment-related research.

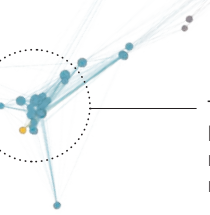

This collaborative group of biological scientists work in relative isolation from the rest of the network.
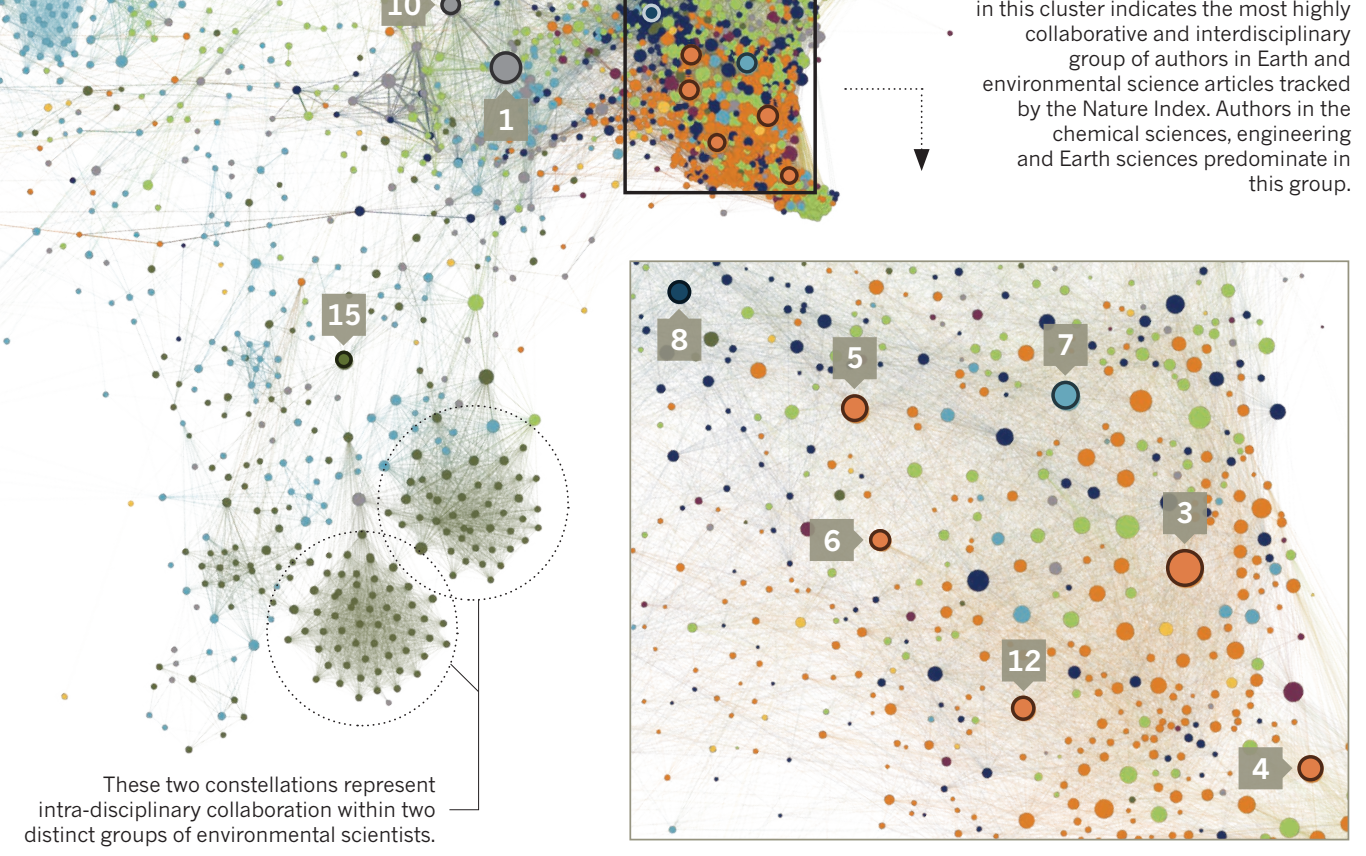

The density of different-coloured nodes in this cluster indicates the most highly collaborative and interdisciplinary group of authors in Earth and environmental science articles tracked by the Nature Index. Authors in the chemical sciences, engineering and Earth sciences predominate in this group.

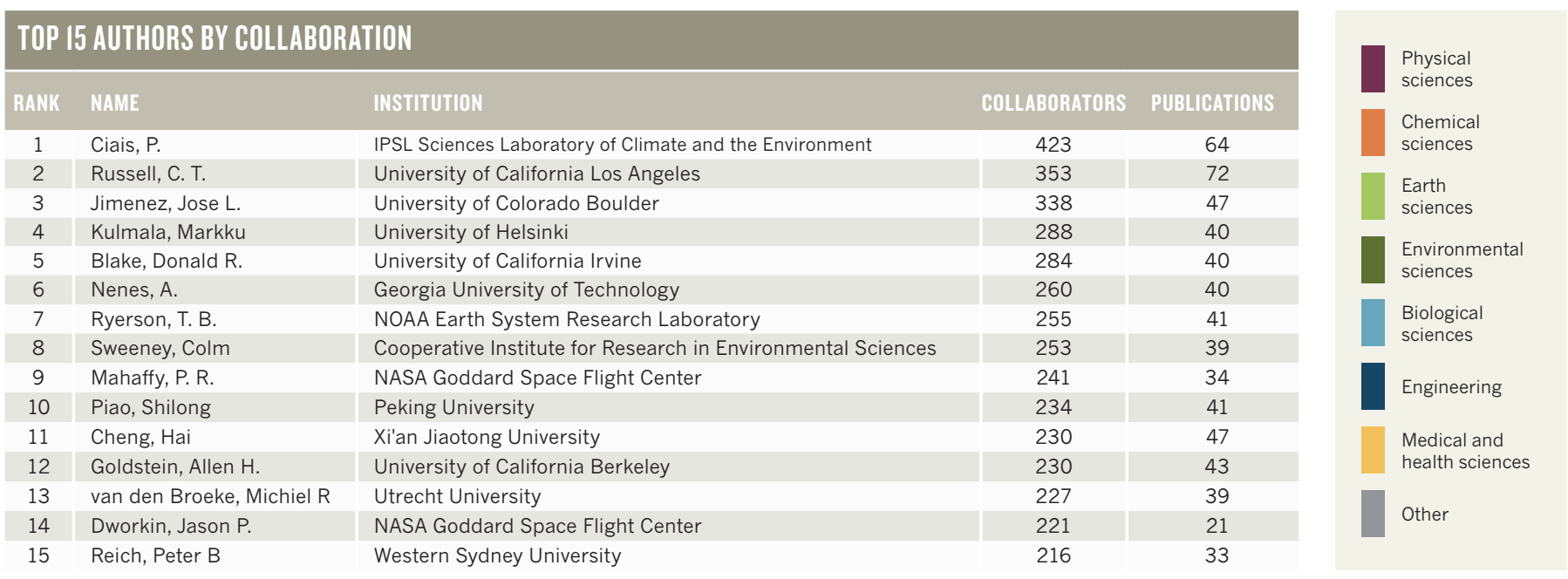

